\title{
Prediction of intraperitoneal adhesions using striae gravidarum and scar characteristics in women undergoing repeated cesarean sections
}

\section{Mohamed Elprince}

Suez Canal University Faculty of Medicine

Omima Tharwat Taha ( $\nabla$ omimatharwat@yahoo.com )

Suez Canal University https://orcid.org/0000-0001-8743-5434

rasha khamees

Suez Canal University Faculty of Medicine

khaled atwa

Suez Canal University Faculty of Medicine

Ahmed gadallah

Suez Canal University Faculty of Medicine noha al-okda

Suez Canal University Faculty of Medicine radwa abdel aal

Suez Canal University Faculty of Medicine Mohamed ibrahim

Suez Canal University Faculty of Medicine Ahmed Aboelroose

Suez Canal University Faculty of Medicine osama ashour

Suez Canal University Faculty of Medicine asmaa elgedawy

Suez Canal University Faculty of Medicine amira elbahie

Suez Canal University Faculty of Medicine hanan ghoneim

Suez Canal University Faculty of Medicine amal ahmed

Suez Canal University Faculty of Medicine 
Keywords: Adhesions, Cesarean scar, Prediction, Striae

Posted Date: August 21st, 2020

DOI: https://doi.org/10.21203/rs.3.rs-58905/v1

License: (c) (1) This work is licensed under a Creative Commons Attribution 4.0 International License. Read Full License

Version of Record: A version of this preprint was published at BMC Pregnancy and Childbirth on April 9th, 2021. See the published version at https://doi.org/10.1186/s12884-021-03763-z. 


\section{Abstract}

Background: The current fact of increasing rates of cesarean deliveries is a catastrophe. Recurrent cesareans result in intraperitoneal adhesions that would lead to maternal morbidity during delivery. Great efforts are directed towards the prediction of intraperitoneal adhesions to provide the best care for laboring women. The aim of the current study was to evaluate the role of abdominal striae and cesarean scar characters in the prediction of intraperitoneal adhesions.

Methods: This was a case- control study conducted in the emergency ward of the obstetrics and gynecology department of a tertiary hospital from June to December 2019. The study was carried on patients admitted to the ward fulfilling particular inclusion and exclusion criteria. The study included two groups, group one was assessed for the presence of striae, and the degree of intraperitoneal adhesions was evaluated during the current cesarean section. Group two included patients without evidence of abdominal striae. They were evaluated for the severity of adhesions also after evaluation of the previous scar. Evaluation of the striae was done using Davey's scoring system. The scar was assessed using the Vancouver Scar Scale. The modified Nair's scoring system was used to evaluate intraperitoneal adhesions.

Results: The study group included 203 women, while the control group included 205 women. There were significant differences in the demographic characters of the recruited patients ( $p$-value 0.001 for almost all variables). The mean Davey score in those with mild, moderate, and severe striae was $1.82 \pm 0.39$, $3.57 \pm 0.5$, and $6.73 \pm 0.94$, respectively ( $p$-value $<0.001$ ). Higher scores for the parameters of the Vancouver scale were present in patients with severe striae $(1.69 \pm 1.01,1.73 \pm 0.57,2.67 \pm 1.23$, and 1.35 \pm 1.06 for scar vascularity, pigmentation, pliability, and height respectively with a p-value of $<0.001$ each). Thick intraperitoneal adhesions were noted significantly in women with severe striae [21 (43.75\%), pvalue $<0.001)$ ]. The Davey's and Vancouver scores showed highly significant predictive performance in the prediction of intraperitoneal adhesions ( $p$-value $<0.001)$.

Conclusion: Abdominal striae and cesarean scar were significant predictors for intraperitoneal adhesions.

\section{Background}

Intra-abdominal adhesions contribute significantly to surgical morbidity in addition to infertility. Cesarean section (CS) is considered one of the most commonly practiced surgical procedure by obstetricians. This raised the assumption that the prediction of intraabdominal adhesions would lead to decreased morbidity (1). Intraabdominal adhesions occur at a $7 \%$ rate after one CS up to $68 \%$ with repeated cesareans (2).

Striae are linear skin changes in areas of skin stretching that cause bothering disfigurement. This occurs because of dermal damage. This stretching occurs due to pregnancy, as well as obesity and Cushing syndrome (3). By examination, they appear as pink- purple and, finally, depressed white lines. 
Histologically, these areas are characterized by a decreased extracellular matrix as well as decreased collagen (4).

The epidermis at the site of the abdominal scars demonstrates delicate well-organized collagen bundles arranged parallel to each other (5). However, scars do not heal similarly, raising the suggestion of a possible relationship to intra-abdominal adhesions (6).

The similarity in the formation of these changes raised the possibility of using abdominal striae and scar appearance as predictive tools for the severity of intra-abdominal adhesions.

\section{Methods}

This study was conducted as a case control study after approval of the research ethics committee of the faculty of medicine, Suez Canal University, in May 2019 with a number of 3849. We recruited patients over six months. The study was carried out in the obstetrics and gynecology department, Suez Canal University Hospitals.

The study was carried on patients admitted to the ward fulfilling the following inclusion and exclusion criteria. Inclusion criteria: - a) patients with previous $C S, b$ ) patients presenting for emergency or elective CS delivery. Exclusion criteria: - a) previous midline surgery, b) history of wound complications, c) history of endometriosis, d) history of pelvic inflammatory disease (PID), e) other abdominal operations other than $\mathrm{CS}, \mathrm{f}$ ) keloid scar formation, g) chronic steroid therapy, h) Cushing disease, i) adrenal hyperplasia, j) Ehlers-Danlos syndrome, k) Marfan syndrome, I) Skin disease as lichen sclerosis, m) Prolonged progesterone use, $n$ ) history of multiple pregnancies, 0 ) history of hydramnios, $p$ ) history of macrosomic babies and q) family history of striae on other parts of the body (breast, hips, and buttocks).

After fulfilling the above criteria, the study included two groups. Group one was assessed for the presence of striae and the degree of intra-abdominal adhesions was evaluated during the current CS. Group two included patients without evidence of abdominal striae and were evaluated for the severity of adhesions after evaluating the previous scar.

All participants gave written informed consent before entering the study. Patients eligible for the study had the following:-

a. Preoperative evaluation: including personal data (age, weight, height, BMI, occupation, level of education, contact information), obstetric history (parity, gestational age, number of previous CS), and any chronic illness. A blood sample for a group and save was withdrawn.

b. Evaluation of striae: using Davey's scoring system (7). In this system, the abdomen is divided into four quadrants using vertical and horizontal lines passing by the umbilicus. Each quadrant is examined for the striae and scored in the following manner:

1. Clear skin, scored as 0 


\section{A moderate number of striae scored as 1}

3. Many striae, scored as 2.

This leads to a total score of $0-8$. The severity of striae is classified as none (0), mild (1-2), moderate (34 ), or severe (5-8). Evaluation of the striae was done by the same researcher using the figure provided by Buchanan et al. (7). Evaluation of intraabdominal adhesions was done by another researcher. Both of them were blinded to the results reported by each other.

c. The scar was assessed using the Vancouver Scar Scale (VSS). This scale evaluates the scar for pigmentation, vascularity, pliability, and height (8).

d. Intraperitoneal adhesions were evaluated by the modified Nair's scoring system. This system classified adhesions into no adhesions, thin filmy adhesions (either single or two bands of adhesions between viscera or from viscera to the abdominal wall), and thick, dense adhesions (more than two bands between viscera or from viscera to the abdominal wall, multiple dense adhesions, or viscera directly adherent to the abdominal wall, regardless of the number or extent of the bands) (9).

Striae and scare characters were evaluated by a researcher who was blinded to the extent of intraperitoneal adhesions.

\section{Statistical Analysis}

Data were statistically described in terms of mean and standard deviation, frequencies (number of cases), and percentages when appropriate. $P$ values less than 0.05 were considered statistically significant. All statistical calculations were done using computer program SPSS (Statistical Package for the Social Science; SPSS Inc., Chicago, IL, USA) release 22 for Microsoft Windows. Chi-square test was used for categorical variables and $(t)$ test for continuous variables with normally distributed data. Nonnormally distributed data were tested using non-parametric tests. Receiver operator characteristic curve was constructed for the Davey's and Vancouver scores to have its cutoff point for the prediction of intraperitoneal adhesions. Sensitivity and specificity were calculated. For the construction of logistic regression models for the prediction of intraperitoneal adhesions, the dependent variable was the presence or absence of adhesions. This was put against all of the variables that it depended upon; hence, there were multiple simple logistic models each with a significant factor. These significant factors were put in a model and factors were removed one by one to produce a best-fit multiple logistic model.

\section{Results}

We recruited patients over six months from June to December 2019. The study group included 203 women, while the control group included 205 women. Data were analyzed according to the grade of Davey's score (mild, moderate, and severe). Patients with no evidence of abdominal striae were considered as controls. Subgroup analysis of the study group was done according to the severity of their 
Davey's' score. There were significant differences in the demographic characters of the recruited patients (p-value 0.001 for almost all variables) (Table 1 ).

The mean Davey score in those with mild, moderate, and severe striae was $1.82 \pm 0.39,3.57 \pm 0.5$, and $6.73 \pm 0.94$, respectively ( $p$-value $<0.001$ ). Higher scores for the parameters of the Vancouver scale were present in patients with severe striae $(1.69 \pm 1.01,1.73 \pm 0.57,2.67 \pm 1.23$, and $1.35 \pm 1.06$ for scar vascularity, pigmentation, pliability, and height respectively with a p-value of $<0.001$ each). Thick intraperitoneal adhesions were noted significantly in women with severe striae [21 (43.75\%), p-value $<0.001$ ) (Table 2).

Women with intraperitoneal adhesions had more vascular, hyperpigmented, less liable, and elevated scars than those without ( $p$-value $<0.001$ each) (Table 3).

The Davey's and Vancouver scores showed highly significant predictive performance in the prediction of intraperitoneal adhesions ( $p$-value < 0.001) (Table 4).

Davey's score of 2.5 had a sensitivity and specificity of $46.31 \%$ and $100.00 \%$, respectively, in the prediction of intraperitoneal adhesions, although insignificant. However, a Vancouver score of 3 was highly significant in the prediction of intraperitoneal adhesions. It had a sensitivity of $84.02 \%$ and specificity of $56.07 \%$ (Table 5).

\section{Discussion}

The overall prevalence of abdominal striae in the studied population was $49.7 \%$ (203/408 women). There were discrepancies in the prevalence of abdominal striae in previous studies with rates of $65.7 \%, 67.7 \%$ among Egyptian women $(10,11)$ and $80 \%$, and $57.9 \%$ among Turkish women $(12,13)$. This would be rendered to different sample sizes as well as different races among the studied populations.

The subanalysis performed for the study group demonstrated significant differences in the demographic characters ( $p$ va2lue 0.001 for almost all variables). In the cohort evaluated in a recent study, there were no differences in the demographic data of the recruited population (10). However, in the cohort evaluated by another researcher, a significant difference was reported between the three groups in age, BMI, weight gain during pregnancy, and fetal weight (11). Such differences would be rendered to different patient grouping (no/mild striae as a group and severe striae as the other one in the former, and no, mild and severe striae in the latter).

Thick intraperitoneal adhesions were noted significantly in women with severe striae [21 (43.75\%), pvalue $<0.001$ with mean Davey score of $6.73 \pm 0.94$ ). This was following the results reported by Abbas et al.; however, they reported that $90 \%$ of women with severe striae had thick adhesions with mean Davey score of $4.25 \pm 3.36$ (10). Another study reported close results to the current one (50\% of patients with severe striae had dense adhesions) (12). This difference would be explained by the different samples included besides; both studies divided patients into two groups only. 
In contention with the current study, there was no difference in peritoneal adhesions in women with or without striae $(14,15)$. However, another study reported higher rates of intraperitoneal adhesions in women with no or mild striae than those with severe striae $(67.3 \%, 65.9 \%$, and $36.3 \%$, respectively) (13). This was explained by the frequent presence of dysfunctional fibroblasts in striae and adhesions. Fibroblasts have an essential role in collagen production in the adhesions; accordingly adhesion formation decreases (13). Besides, the different tools for evaluation of the striae would result in variable results, especially when incorporating the striae color, which was not evaluated in the current study.

The current study reported intraperitoneal adhesions occurring in 194/ 408 (47.5\%) of the studied population. This was lower than reported by others $(59.6 \%$ and $54.3 \%)(11,13)$. However, too much higher rates of intraperitoneal adhesions were reported by Abbas et al. and Khalifi et al. (87\% and $73.5 \%$, respectively) $(10,16)$. This disparity in results would be rendered to differences in surgeons, techniques, and suture materials used in the operations.

Women with severe striae and those with intraperitoneal adhesions had more vascularized, hyperpigmented, less pliable and elevated CS scars $(1.69 \pm 1.01,1.73 \pm 0.57,2.67 \pm 1.23$, and $1.35 \pm 1.06$ respectively with a p-value of $<0.001$ each). This contradicted the results reported by previous research, which stated that flat unpigmented scars were more prominent in women with striae. They explained this by the overexpression of transforming growth factor- Beta. It leads to deficient elastin production, which is a causative factor in the formation of abdominal striae (14).

To achieve perfect scar remodeling, collagen fibers are organized in a parallel fashion. While, in elevated scars, increased collagen production is noted. This was thought to arise from variability in transforming growth factor-beta, which plays an essential role in the formation of hypertrophic scars as well as intraperitoneal adhesions (13). Scar width and appearance showed significant association with dense intraperitoneal adhesions ( $p$-value 0.001 , and 0.002 respectively) (15). Depressed hypopigmented scars were also associated with adhesions, which were assumed to arise from the inward traction from the adhesion bands $(17,18)$. Besides, in a meta-analysis of numerous studies, they reported that flat scars were indicative of absent adhesions while depressed ones were associated with adhesions (19). Conflicting results exist as elevated scars were found to be associated with more adhesions all over the abdomen than flat or depressed ones (20).

The Davey's and Vancouver scores showed highly significant predictive performance in the prediction of intraperitoneal adhesions ( $p$-value $<0.001$ ). Davey's score of $\geq 2.5$ had a sensitivity and specificity of $46.31 \%$ and $100.00 \%$, respectively, in the prediction of intraperitoneal adhesions. This was similar to the results reported previously, where Davey score of 2 was considered a significant risk factor in predicting intraperitoneal adhesions. Also, the best cut off was $\geq 3$ with reported sensitivity and specificity of $64 \%$ and $51.3 \%$, respectively (10). However, Abdelaal et al. reported that abdominal striae were not considered a predictor for abdominal adhesions while the number of previous CS did (11).

Research implications: The role of the scar characters in relation to intraperitoneal adhesions needs to be evaluated deeply. 
Strengths and limitations of the study: Strengths included a large sample size of recruited patients; subanalysis of the patients with striae into mild, moderate and severe provided more robust results, evaluation of the striae and CS scar using simple scoring systems, and the recruited population was of the same ethnicity. However, we did not have any previous medical records about the operative notes of the previous deliveries since most of them delivered in private sittings outside the hospital previously. We did not consider the inter-pregnancy interval as a risk factor for adhesion formation. Also, we did not evaluate the color of the striae.

\section{Conclusion}

Abdominal striae and CS scar were significant predictors for intraperitoneal adhesions. Women with severe striae had thick intraperitoneal adhesions. Women with intraperitoneal adhesions had more vascular, hyperpigmented, less pliable and elevated scars.

\section{Abbreviations}

\begin{tabular}{cl} 
CS & Cesarean section \\
\hline PID & Pelvic inflammatory disease \\
\hline BMI & Body mass index \\
\hline VSS & Vancouver Scar Scale
\end{tabular}

\section{Declarations}

Ethical approval and consent to participate: This study was conducted after approval of the research ethics committee of the faculty of medicine, Suez Canal University, in May 2019 with a number of 3849\#. All procedures performed in the study were following the ethical standards of the institutional and/or national research committee and with the 1964 Helsinki declaration and its later amendments or comparable ethical standards. This article does not contain any studies with animals performed by any of the authors. Informed written consent was obtained from all participants before enrollment in the study.

Consent for publication: not applicable.

Availability of data and materials: The datasets used and/or analyzed during the current study available from the corresponding author on reasonable request. All data generated or analyzed during this study are included in this published article

Competing interest: None

Funding: self-funded research 
Authors' contributions: OTT: Protocol/project development, Data collection and management, manuscript writing/editing. M E: Data collection and analysis. AAA: Data collection and management, Manuscript writing/editing. HMG: Data collection and management, Data analysis, Manuscript writing/editing. REK: Data collection and management, Manuscript writing/editing. OEA: Data collection and management, Manuscript writing/editing. AME: Data collection and management, Data analysis, Manuscript writing/editing. AAA: Data collection and management, Data analysis, Manuscript writing/editing. MFI: Data collection and management, Data analysis, Manuscript writing/editing. RMA: Data collection and management, Data analysis, Manuscript writing/editing. NA: Protocol/project development, Data collection and management, manuscript writing/editing. AMG: Protocol/project development, Data collection and management, manuscript writing/editing. AME: Data collection and management, Data analysis, Manuscript writing/editing. KAA: Data collection and management, Data analysis, Manuscript writing/editing. All authors have read and approved the manuscript.

Acknowledgment: We are grateful to Professor Zakia M. Ibrahim for her generous inspiration and support throughout conducting the whole research.

\section{References}

1. Murphy DJ, Stirrat GM, Heron J; ALSPAC Study Team. The relationship between Caesaean section and subfertility in a population-based sample of 14541 pregnancies. Hum Reprod 2002; 17:19141917.

2. Rossouw JN, Hall D, Harvey J. Time between skin incision and delivery during cesarean. Int $\mathrm{J}$ Gynaecol Obstet 2013; 121: 82-85.

3. Rachel EB Watson. Stretching the Point: An Association between the Occurrence of Striae and Pelvic Relaxation? Journal of Investigative Dermatology 2006; 126, 1688-1689. doi:10.1038/sj.jid.5700316

4. Watson RE, Parry EJ, Humphries JD, et al. Fibrillin microfibrils are reduced in skin exhibiting striae distensae. Br J Dermatol 1998; 138:931-7.

5. LarsonA, NautaK, KawaiM, LongakerH, Lorenz Scarring and scarless wound healing. Woodhead Publishing Series in Biomaterials 2011, Pages 77-111.

6. Dogan NU, Haktankacmaz SA, Dogan S, Ozkan O, Celik H, Eryilmaz OG, Doganay M, Gulerman C. A reliable way to predict intra-abdominal adhesions at repeat cesarean delivery: scar characteristics. 2011: Acta Obstetricia et Gynecologica Scandinavica; 90 (2011) 531-534.

7. Buchanan $\mathrm{K}$, Fletcher HM, Reid M. Prevention of striae gravidarum with cocoa butter cream. Int J Gynaecol Obstet 2010; 108:65-8.

8. Sullivan T, Smith J, Kermode J, Mclver E, Courtemanche DJ. Rating the burn scar.1990; J Burn Care Rehabil 11: 256-260.

9. Kahyaoglu I, Kayikcioglu F, Kinay T. et al. Abdominal scar characteristics: do they predict intraabdominal adhesions with repeat cesarean deliveries? J Obstet Gynaecol Res. 2014; 40:1643-1648. 
10. Abbas AM, Khalaf M, Abdel-Reheem F, El-Nashar I. Prediction of pelvic adhesions at repeat cesarean delivery through assessment of striae gravidarum score: A cross-sectional study. Journal of Gynecology Obstetrics and Human Reproduction 49 (2020) 101619.

11. Abd-Elaal NK, El Kelani OA, Saif-Elnasr IA, Elkhyat AM. The relationship between striae gravidarum and intra-abdominal adhesions in pregnant women with previous cesarean section. Int J Curr Res 2018;10(1):64521-7.

12. Cakir Gungor AN, Oguz S, Hacivelioglu S, Isik S, Uysal A, Gencer M, et al. Predictive value of striae gravidarum severity for intraperitoneal adhesions or uterine scar healing in patients with previous caesarean delivery. J Matern Fetal Neonatal Med 2014; c 27:1312-5.

13. Dogan A, Etras IE, Uyar I, Karaca I, Bozgeyik B, Toz E, et al. Preoperative association of abdominal striae gravidarum with intra-abdominal adhesions in pregnant women with a history of previous cesarean section: a cross-sectional study. Geburtsh Frauenheilk 2016; 76:268-72.

14. Celik EY, Ersoy AO, Ersoy E, Yoruk O, Tokmak A, Tasci Y. Is striae gravidarum related to cesarean scar and peritoneal adhesions? PakJ Med Sci. 2018; 34 (3):568-73.

15. Jaafar ZA, Obeid RZ, Salman DA. Skin markers and the prediction of intraabdominal adhesion during second Cesarean delivery. Ginekologia Polska: 2019, vol. 90, no. 6, 325-330.

16. Khalifi A, Meddeb S, Kouira M, Boukadida A, Hachani F, Chachia S, et al. Post-cesarean parietal scar characteristics are predictive of pelvic adhesions. A prospective cohort study. J Gynecol Obstet Biol Reprod (Paris) 2015; 44:621-31.

17. Salim RY, Kadan Z, Nachum Edelstein S, Shalev E. Abdominal scar characteristics as a predictor of intra-abdominal adhesions at repeat cesarean delivery. Fertil Steril 2008;90:2324-7.

18. Cim N, Elci E, Guneş Elci G, et al. Are the skin scar characteristics and closure of the parietal peritoneum associated with pelvic adhesions? Turk J Obstet Gynecol. 2018; 15(1): 28-32, doi: 10.4274/tjod.55491, indexed in Pubmed: 29662713.

19. Pergialiotis V, Frountzas $\mathbf{M}$, Siotos $\mathbf{C}$, et al. Cesarean wound scar characteristics for the prediction of pelvic adhesions: a meta-analysis of observational studies. J Matern Fetal Neonatal Med. 2017; 30(4): 486-491, doi: 10.1080/14767058.2016.1176135, indexed in Pubmed: 27072887.

20. Kokanal D, Kokanal MK, Topcu HO, Ersak B, Tasc Y. Are the cesarean section skin scar characteristics associated with intraabdominal adhesions located at surgical and non-surgical sites, J Gynecol Obstet Hum Reprod 2019; 48 (10); 839-843. https://doi.org/10.1016/j.jogoh.2019.03.026.

\section{Tables}

Table 1: Patient demographic data according to the distribution of abdominal striae 


\begin{tabular}{|c|c|c|c|c|c|c|}
\hline \multicolumn{2}{|c|}{ Davey's score grade } & None & Mild & Moderate & Severe & $\begin{array}{l}\mathrm{p}- \\
\text { value }\end{array}$ \\
\hline \multicolumn{2}{|c|}{ Age (years) (Mean \pm SD) } & $\begin{array}{l}27.92 \pm \\
3.1\end{array}$ & $\begin{array}{l}29.5 \pm \\
5.76\end{array}$ & $\begin{array}{l}31.96 \pm \\
5.67\end{array}$ & $\begin{array}{l}33.23 \pm \\
4.68\end{array}$ & $<0.001$ \\
\hline \multicolumn{2}{|c|}{ Parity (Mean \pm SD) } & $\begin{array}{l}1.28 \pm \\
0.45\end{array}$ & $\begin{array}{l}2.17 \pm \\
1.31\end{array}$ & $2.57 \pm 1.53$ & $2.75 \pm 1.55$ & $\leq 0.001$ \\
\hline \multicolumn{2}{|c|}{$\begin{array}{l}\text { Number of previous CS (Mean } \pm \\
\text { SD) }\end{array}$} & $\begin{array}{l}1.22 \pm \\
0.42\end{array}$ & $\begin{array}{l}1.72 \pm \\
0.85\end{array}$ & $1.87 \pm 0.91$ & $2.52 \pm 1.38$ & $\leq 0.001$ \\
\hline \multicolumn{2}{|c|}{ Weight (kg) (Mean \pm SD) } & $\begin{array}{l}76.46 \pm \\
11.66\end{array}$ & $\begin{array}{l}80.14 \pm \\
10.55\end{array}$ & $\begin{array}{l}86.22 \pm \\
11.05\end{array}$ & $\begin{array}{l}84.38 \pm \\
13.49\end{array}$ & $\leq 0.001$ \\
\hline \multicolumn{2}{|c|}{ Height (cm) (Mean \pm SD) } & $\begin{array}{l}164.98 \pm \\
6.92\end{array}$ & $\begin{array}{l}162.62 \pm \\
5.38\end{array}$ & $\begin{array}{l}162.96 \pm \\
5.58\end{array}$ & $\begin{array}{l}164.71 \pm \\
4.27\end{array}$ & $\leq 0.001$ \\
\hline \multicolumn{2}{|c|}{$\begin{array}{l}\text { Body mass index }\left(\mathrm{kg} / \mathrm{m}^{\wedge} 2\right) \\
\text { (Mean } \pm \text { SD) }\end{array}$} & $\begin{array}{l}28.11 \pm \\
4.2\end{array}$ & $\begin{array}{l}30.41 \pm \\
4.47\end{array}$ & $\begin{array}{l}32.52 \pm \\
4.21\end{array}$ & $\begin{array}{l}31.05 \pm \\
4.67\end{array}$ & $\leq 0.001$ \\
\hline \multirow[t]{3}{*}{ Education ( $\mathrm{N} \%$ ) } & None & $\begin{array}{l}34 \\
(16.59 \%)\end{array}$ & $\begin{array}{l}19 \\
(17.43 \%)\end{array}$ & $\begin{array}{l}16 \\
(34.78 \%)\end{array}$ & $\begin{array}{l}11 \\
(22.92 \%)\end{array}$ & \multirow[t]{3}{*}{$\underline{0.001}$} \\
\hline & Middle & $\begin{array}{l}92 \\
(44.88 \%)\end{array}$ & $\begin{array}{l}66 \\
(60.55 \%)\end{array}$ & $\begin{array}{l}16 \\
(34.78 \%)\end{array}$ & $\begin{array}{l}15 \\
(31.25 \%)\end{array}$ & \\
\hline & High & $\begin{array}{l}79 \\
(38.54 \%)\end{array}$ & $\begin{array}{l}24 \\
(22.02 \%)\end{array}$ & $\begin{array}{l}14 \\
(30.43 \%)\end{array}$ & $\begin{array}{l}22 \\
(45.83 \%)\end{array}$ & \\
\hline \multirow[t]{3}{*}{ Job (N \%) } & Housewife & $\begin{array}{l}149 \\
(72.68 \%)\end{array}$ & $\begin{array}{l}82 \\
(75.23 \%)\end{array}$ & $\begin{array}{l}40 \\
(86.96 \%)\end{array}$ & $\begin{array}{l}39 \\
(81.25 \%)\end{array}$ & \multirow[t]{3}{*}{0.11} \\
\hline & Worker & $\begin{array}{l}56 \\
(27.32 \%)\end{array}$ & $\begin{array}{l}26 \\
(23.85 \%)\end{array}$ & $5(10.87 \%)$ & $9(18.75 \%)$ & \\
\hline & Employee & $0(0 \%)$ & $1(0.92 \%)$ & $1(2.17 \%)$ & $0(0 \%)$ & \\
\hline
\end{tabular}

Table 2: Scare characters and intrabdominal adhesions in relation to abdominal striae 


\begin{tabular}{|c|c|c|c|c|c|c|}
\hline \multicolumn{2}{|c|}{ Davey's score grade } & $\begin{array}{l}\text { None } \\
(205)\end{array}$ & $\begin{array}{l}\text { Mild } \\
\text { (109) }\end{array}$ & $\begin{array}{l}\text { Moderate } \\
\text { (46) }\end{array}$ & $\begin{array}{l}\text { Severe } \\
\text { (48) }\end{array}$ & $\begin{array}{l}\mathrm{p}- \\
\text { value }\end{array}$ \\
\hline \multicolumn{2}{|c|}{ Vascularity (Mean \pm SD) } & $\begin{array}{l}0.61 \pm \\
0.82\end{array}$ & $\begin{array}{l}0.89 \pm \\
0.64\end{array}$ & $1.07 \pm 0.8$ & $\begin{array}{l}1.69 \pm \\
1.01\end{array}$ & $\leq 0.001$ \\
\hline \multicolumn{2}{|c|}{ Pigmentation (Mean \pm SD) } & $\begin{array}{l}0.84 \pm \\
0.83\end{array}$ & $\begin{array}{l}1.01 \pm \\
0.73\end{array}$ & $1.54 \pm 0.62$ & $\begin{array}{l}1.73 \pm \\
0.57\end{array}$ & $\leq 0.001$ \\
\hline \multicolumn{2}{|c|}{ Pliability (Mean \pm SD) } & $\begin{array}{l}1.11 \pm \\
0.99\end{array}$ & $\begin{array}{l}1.34 \pm \\
1.05\end{array}$ & $1.83 \pm 1.34$ & $\begin{array}{l}2.67 \pm \\
1.23\end{array}$ & $\leq 0.001$ \\
\hline \multicolumn{2}{|c|}{ Height $(\mathrm{mm})($ Mean \pm SD) } & $\begin{array}{l}0.56 \pm \\
0.76\end{array}$ & $\begin{array}{l}0.77 \pm \\
0.73\end{array}$ & $1 \pm 0.89$ & $\begin{array}{l}1.35 \pm \\
1.06\end{array}$ & $\leq 0.001$ \\
\hline \multicolumn{2}{|c|}{ Total score (/13) (Mean \pm SD) } & $\begin{array}{l}3.12 \pm \\
2.97\end{array}$ & $\begin{array}{l}4.01 \pm \\
2.52\end{array}$ & $5.43 \pm 2.75$ & $\begin{array}{l}7.44 \pm \\
2.92\end{array}$ & $\leq 0.001$ \\
\hline \multicolumn{2}{|c|}{ Davey's score (Mean \pm SD) } & $0 \pm 0$ & $\begin{array}{l}1.82 \pm \\
0.39\end{array}$ & $3.57 \pm 0.5$ & $\begin{array}{l}6.73 \pm \\
0.94\end{array}$ & $\leq 0.001$ \\
\hline \multirow[t]{3}{*}{$\begin{array}{l}\text { Intraperitoneal } \\
\text { adhesions (N\%) }\end{array}$} & None & $\begin{array}{l}171 \\
(83.41 \%)\end{array}$ & $\begin{array}{l}24 \\
(22.02 \%)\end{array}$ & $9(19.57)$ & $\begin{array}{l}10 \\
(20.83)\end{array}$ & \multirow[t]{3}{*}{$\leq 0.001$} \\
\hline & $\begin{array}{l}\text { Thin } \\
\text { filmy }\end{array}$ & $\begin{array}{l}34 \\
(16.59 \%)\end{array}$ & $\begin{array}{l}74 \\
(67.89 \%)\end{array}$ & $24(52.17)$ & $\begin{array}{l}17 \\
(35.42)\end{array}$ & \\
\hline & Thick & $0(0 \%)$ & $\begin{array}{l}11 \\
(10.09 \%)\end{array}$ & $13(28.26)$ & $\begin{array}{l}21 \\
(43.75)\end{array}$ & \\
\hline
\end{tabular}

Table 3: Scar characters in women with intraperitoneal adhesions 


\begin{tabular}{|c|c|c|c|c|}
\hline \multicolumn{2}{|c|}{ Adhesion occurrence } & \multirow{2}{*}{$\begin{array}{l}\text { No } \\
\text { n (\%) }\end{array}$} & \multirow{2}{*}{$\begin{array}{l}\text { Yes } \\
\text { n (\%) }\end{array}$} & \multirow[t]{2}{*}{ p-value } \\
\hline Variable & Attribute & & & \\
\hline \multirow[t]{5}{*}{ Vascularity } & Normal & $127(59.35)$ & 32 (16.49) & \multirow[t]{5}{*}{$\leq 0.001$} \\
\hline & Red & 57 (26.64) & $114(58.76)$ & \\
\hline & Pink & $14(6.54)$ & 38 (19.59) & \\
\hline & Purple & $16(7.48)$ & $10(5.15)$ & \\
\hline & Total & $214(100)$ & $194(100)$ & \\
\hline \multirow[t]{4}{*}{ Pigmentation } & Normal & $96(44.86)$ & 28 (14.43) & \multirow[t]{4}{*}{$\leq 0.001$} \\
\hline & Hypopigmented & $44(20.56)$ & 88 (45.36) & \\
\hline & Hyperpigmented & 74 (34.58) & 78 (40.21) & \\
\hline & Total & $214(100)$ & $194(100)$ & \\
\hline \multirow[t]{7}{*}{ Pliability } & Normal & $66(30.84)$ & $16(8.25)$ & \multirow[t]{7}{*}{$\leq 0.001$} \\
\hline & Supple & $90(42.06)$ & 83 (42.78) & \\
\hline & Yielding & 47 (21.96) & 36 (18.56) & \\
\hline & Firm & $0(0)$ & $42(21.65)$ & \\
\hline & Ropes & $11(5.14)$ & $8(4.12)$ & \\
\hline & Contracture & $0(0)$ & $9(4.64)$ & \\
\hline & Total & $214(100)$ & $194(100)$ & \\
\hline \multicolumn{2}{|l|}{ Height (mm) } & $0.5 \pm 0.75$ & $1.05 \pm 0.85$ & $\leq 0.001$ \\
\hline \multicolumn{2}{|c|}{ Total score (/13) } & $3.08 \pm 3.08$ & $5.28 \pm 2.81$ & $\leq 0.001$ \\
\hline
\end{tabular}

Table 4: Linear regression model for the prediction of intra-peritoneal adhesions

\begin{tabular}{|lllll|}
\hline Variables & $\boldsymbol{\beta}$ & P-value & OR & 95\% Cl OR \\
\hline Age (years) & 0.217 & $\underline{\mathbf{0 . 0 0 1}}$ & 1.243 & $(1.156-1.335)$ \\
\hline Education & -2.093 & $\underline{\mathbf{0 . 0 0 1}}$ & 0.123 & $(0.071-0.215)$ \\
\hline Body mass index & 0.083 & $\underline{\mathbf{0 . 0 0 8}}$ & 1.086 & $(1.022-1.155)$ \\
\hline Vancouver score & 0.236 & $\underline{\mathbf{L 0 . 0 0 1}}$ & 1.267 & $(1.119-1.433)$ \\
\hline Davey score & 0.479 & $\underline{\mathbf{L 0 . 0 0 1}}$ & 1.615 & $(1.374-1.898)$ \\
\hline
\end{tabular}


Table 5: Cut- off value for the Davey score and the Vancouver score:

\begin{tabular}{|c|c|c|c|c|}
\hline \multirow[b]{2}{*}{ Statistic } & \multicolumn{2}{|c|}{ Davey score } & \multicolumn{2}{|c|}{ Vancouver score } \\
\hline & Value & $95 \% \mathrm{Cl}$ & Value & $95 \% \mathrm{Cl}$ \\
\hline Cut-off point & 2.5 & $3.09-3.66$ & 3 & \\
\hline p-value & 0.914 & & $<0.001$ & \\
\hline Area under curve (\%) & 49.5 & $39.2-59.7$ & 71.9 & 0.672 to 0.762 \\
\hline Sensitivity (\%) & $46.31 \%$ & $39.30 \%$ to $53.42 \%$ & 84.02 & $78.1-88.9$ \\
\hline Specificity (\%) & $100.00 \%$ & $98.22 \%$ to $100.00 \%$ & 56.07 & $49.1-62.8$ \\
\hline Positive Predictive Value (\%) & $100.00 \%$ & & 63.4 & $59.6-67.1$ \\
\hline Negative Predictive Value (\%) & $67.26 \%$ & $64.39 \%$ to $70.01 \%$ & 79.5 & $73.3-84.5$ \\
\hline
\end{tabular}

